\title{
Calcific Plug Obstructing the Thoracic Aorta
}

\author{
Federico Del Re, MD ${ }^{1} \quad$ Andrea De Martino, $M^{1} \quad$ Giosuè Falcetta, $M^{1} \quad$ Uberto Bortolotti, MD ${ }^{1}$
}

1 Section of Cardiac Surgery, Department of Cardiac Thoracic and Vascular Surgery, University Hospital, Pisa, Italy

AORTA 2020;8:23-24
Address for correspondence Uberto Bortolotti, MD, Sezione Autonoma di Cardiochirurgia Universitaria, Università di Pisa, Via Paradisa, 2, 56124 Pisa, Italy (e-mail: uberto.bortolotti@med.unipi.it).

\section{Abstract Keywords \\ - aortic occlusion \\ - hypertension \\ - aortic syndrome}

\begin{abstract}
We describe a case of a 57-year-old woman with occlusion of the thoracic aorta due to a calcific plug as an unusual cause of refractory hypertension. Middle aortic syndrome, also known as "coral reefaorta," defined as a clinical condition caused by thoracic and/or abdominal aortic stenosis, requires peculiar treatment strategies representing a complex surgical challenge.
\end{abstract}

Middle aortic syndrome is defined as a clinical condition caused by thoracic and/or abdominal aortic stenosis. ${ }^{1}$ Congenital coarctation, Takayasu or giant cell arteritis, neurofibromatosis, and Williams syndrome represent the most frequent etiologies.

We describe a 57-year-old woman with refractory hypertension of the upper body as initial presentation of mid- aortic syndrome due to an extensive calcified plug causing occlusion of the descending thoracic aorta.

The patient was referred to our hospital for pulmonary edema due to a hypertensive crisis. Her past history included a subarachnoid hemorrhage successfully treated by clipping of a saccular aneurysm of the right internal carotid artery. The electrocardiogram showed signs of left ventricular

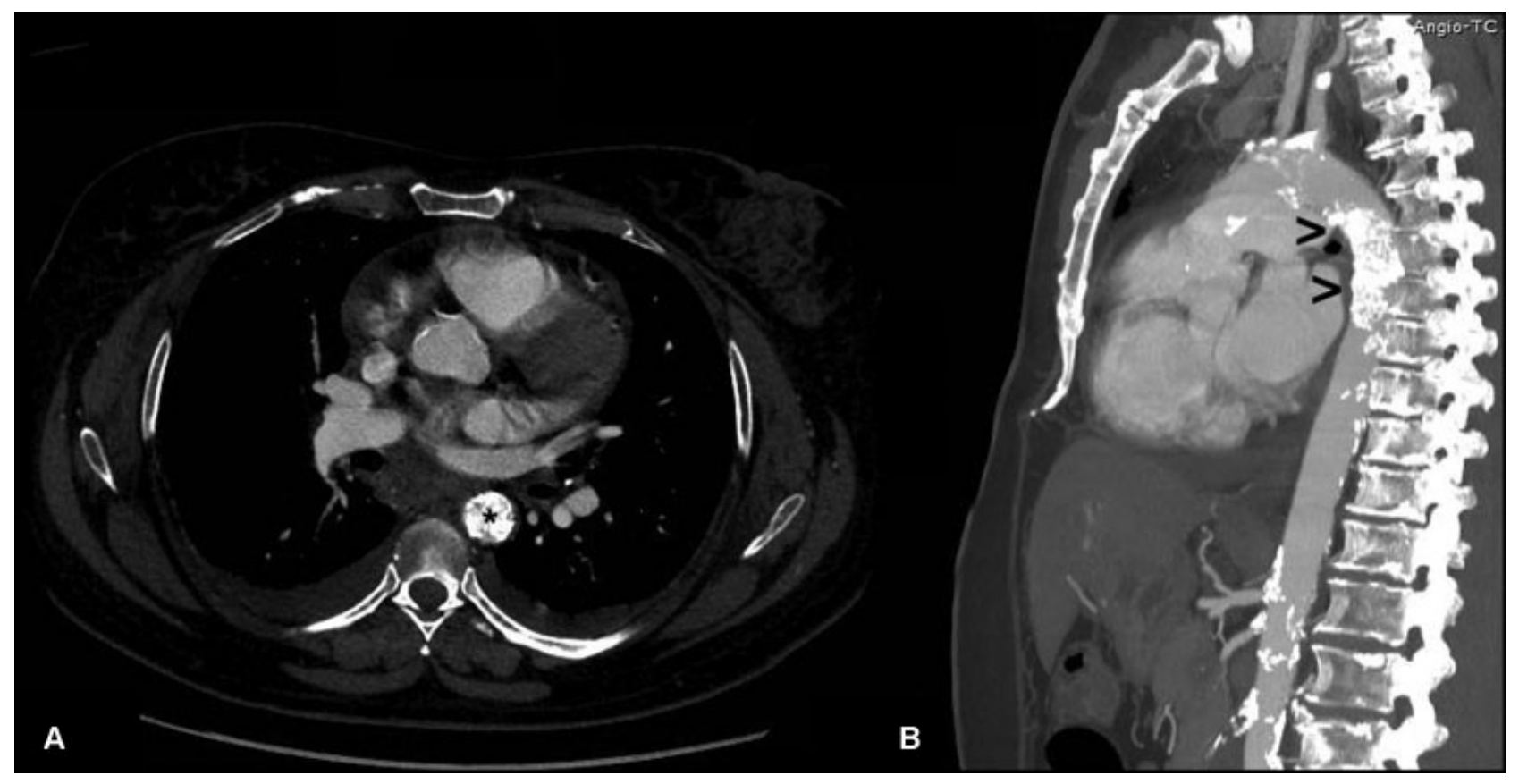

Fig. 1 Computed tomography showing occlusion of the descending thoracic aorta (axial view in panel A and sagittal view in Panel B) by a massive calcific plug (asterisk in Panel A and arrowheads in Panel B). Diffuse calcification of the entire aorta is also present.

received

June 19, 2018

accepted after revision

November 18, 2019
DOI https://doi.org/

$10.1055 / \mathrm{s}-0039-1701000$. ISSN 2325-4637.
Copyright $@ 2020$ by Thieme Medical Publishers, Inc., 333 Seventh Avenue, New York, NY 10001, USA. Tel: +1(212) 760-0888.

\section{License terms}

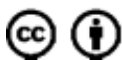


24 Calcific Aorta Del Re et al.

hypertrophy and the chest X-ray evidenced moderate cardiac enlargement. Arterial blood pressure in the upper extremities was $200 \mathrm{~mm} \mathrm{Hg}$ systolic but only $80 \mathrm{~mm} \mathrm{Hg}$ in the lower limbs, with an ankle/brachial index of 0.4 . An echocardiography-Doppler study showed $>70 \%$ stenosis at the origin of both renal arteries.

Computed tomography evidenced diffuse calcification involving the entire aorta with a calcific plug creating obstruction of the descending thoracic aorta below the origin of the left subclavian artery (-Fig. 1 ).

Endovascular treatment of the occluded aorta along with direct surgical repair due to the extensive calcifications of the aortic wall was considered too hazardous.

In this case severe hypertension was considered due to a combination of aortic occlusion and bilateral stenosis of the renal arteries. In the absence of symptoms related to abdominal and lower limb ischemia, endovascular treatment of renal artery stenosis has been scheduled. Angioplasty of the renal arteries was not performed since the patient died 6 months later because of acute bowel infarction.

Alternative surgical procedures, in case of ischemic symptoms, may include an apicoaortic conduit or an axillobifemoral bypass.
This case describes an uncommon cause of middle aortic syndrome, also known as "coral reef aorta" which can represent an extremely difficult surgical challenge. In adult patients with refractory arterial hypertension and anklebrachial index suggestive for aortic obstruction, a complete tomographic evaluation of the aorta is mandatory. ${ }^{2}$

\section{Funding}

None.

\section{Conflict of Interest}

The authors declare no conflict of interest related to this article.

\section{Acknowledgment}

None.

\section{References}

1 Sen PK, Kinare SG, Engineer SD, Parulkar GB. The middle aortic syndrome. Br Heart J 1963;25:610-618

2 Connolly JE, Wilson SE, Lawrence PL, Fujitani RM. Middle aortic syndrome: distal thoracic and abdominal coarctation, a disorder with multiple etiologies. J Am Coll Surg 2002;194(06):774-781 